\title{
Discussion: Students" view on their education and the future
}

Mike Bather BSC (Hons), MA, MIStructE, CEng, SFHEA Senior Lecturer, Structural Engineering, University of Bolton, Bolton, UK (corresponding author: m.bather@bolton.ac.uk)

Paul Drenning BSC

Graduate Student, Auburn University, AL, USA
John Parkin BSC, ACGI MSc, PhD, PGCE, CEng, FICE, FCIHT, FCILT, FHEA

Professor of Transportation Engineering, University of the West of England, Bristol, UK

\section{Contribution by P. Drenning}

As a recent university graduate with a Bachelor's degree in civil engineering, the realisation that 5 years of education is not sufficient to prepare oneself for the municipal engineering job force is very demoralising. The broad outline of skill sets required for the future is helpful, but daunting. From reading the article it would seem that many of these can be learned from a traditional graduate degree programme, but how does one avoid overspecialisation in a field that evidently requires a jack-of-all-trades approach? Many of the nontechnical and interpersonal skills would be best learned in-house through specific job training programmes, but how can entry-level engineers, such as the author himself, be best prepared to pass the initial test of being hired without going bankrupt as a result of paying for many years of expensive education?

This sounds like classic career advice, but it is important to provide answers to these questions in order for new, young workers to be able to adapt to the changing needs of cities in this tumultuous climate era and be part of the solution.

\section{Editor and original author's reply}

The themed issue 'Future skill needs in municipal engineering' consists of seven papers. Two papers provided opinion on degree programmes; three provided views on the skills required for engineers in practice and another two focused on the specific issues at play in developing countries. The key, perhaps, to diffusing Paul Drenning's concern about being daunted by the skill needs of engineers is perhaps best expressed in Mike Bather's paper (Bather, 2011). Bather (2011) talks about how part-time students want to relate their university learning to their practical experience. The experience that most part-time students have because they are in the early part of their career is usually more limited than the breadth of a university curriculum. Bather (2011) says, however, that 'Ironically, the converse is likely to be true at the end of a career in civil engineering: the breadth of work undertaken is greater than that encountered at university'. This is clearly incontrovertibly true: there is no way that a lifetime's knowledge and skill can be acquired through the educational system during early adult life.

A university education in engineering will provide the necessary base knowledge and an understanding of the engineering principles and some skill in their application. It will also, to varying extents depending on the programme of study, provide education in a wider variety of relevant subject areas, such as construction processes and management. A graduate engineer will engage in a period of initial professional development, carefully supervised by his or her employer. He/she will then need to engage continuously in enhancing knowledge and skills throughout his or her career. As each year passes, the engineer is building in experience and in the consolidation and improvement of skills.

Whatever skills someone may have at the time of professional employment will always need to be developed and enhanced. This enhancement is possible in people with the right behaviours towards education and professional development. A good recruitment process should be very much about identifying appropriate behaviours.

The author hopes that Paul Drenning, rather than being daunted by the future, can be excited by its possibilities.

\section{Authors' reply}

Paul raises several large issues in a couple of short paragraphs. First, 5 years of full-time education cannot be the necessary and sufficient preparation for any profession, not just civil engineering. It may be, perhaps, demoralising, but true. However, a degree in civil engineering is a great foundation to step into the working world of civil engineers. Graduates are in a superb position to advance their learning and their careers from their first day of employment. Second, for students and young professionals, the author can see how a comprehensive 
list of skills is daunting; however, many skills are learned at work; this is achieved through application and reflection. Paul mentions in-house and job-specific training programmes, which are, of course, essential and useful; however, the author would argue that the vast majority of learning that takes place during the initial professional development of engineers is achieved on the job, through practical experience. Third, as for avoiding specialisation, the author's personal feeling is that a civil engineering degree presently is a mix of disparate subjects ranging from structural design and planning, construction management, material science and geotechnics, and many more such as contracts management, transport analysis and highway design. This makes overspecialisation at the undergraduate level a difficult proposition and probably something not to worry over. Beyond university, despite the wide variety of work carried out by civil and municipal engineers, there is a common thread connecting their working lives and one could call this the application of engineering judgement. This crucial attribute comprises a mix of knowledge, experience, skills, communication and clarity of thought and is developed during one's working life, building on the foundations of a degree. This is something that you will recognise in others when encountered and is something to be admired. You are already well on the road to the development of this attribute.

\section{REFERENCE}

Bather M (2011) Students' view on their education and the future. Proceedings of the Institution of Civil Engineers Municipal Engineer 164(ME4): 209-219, http://dx.doi.org/ 10.1680/muen.2011.164.4.209. 